\title{
Evaluation of Socio-demographic and Lifestyle Factors Among Subtypes of Irritable Bowel Syndrome
}

\author{
Chowdhury SR ${ }^{1}$, Safwath SA ${ }^{2}$, Ghosh $\mathrm{DK}^{3}$, Mahmuduzzaman $\mathrm{M}^{4}$, Saha $\mathrm{M}^{5}$, Alam MJ ${ }^{6}$, M Choudhury UA ${ }^{7}$
}

Conflict of Interest: None Contributions by authors: All authors contributed from protocol to write up the article.

Received: 15 April 2017

Accepted: 20 May 2017

www.banglajol.info/index.php/JSSMC

Key words: Irritable bowel syndrome, Rome-III criteria, Health enhancing physical activity,

\begin{abstract}
Background: Irritable bowel syndrome (IBS) is one of the most common functional gastrointestinal disorder with absence of organic damages to the intestine. The pathophysiology of IBS is still not completely understood, but in some cases psychological disorders may affect the onset and outcome of IBS. Some studies have found disparities between subtypes of irritable bowel syndrome (IBS) regarding socio-demographic characteristics and lifestyle factors.
\end{abstract}

Methods: This cross-sectional study aimed to investigate whether there are differences in sociodemographic and lifestyle factors including smoking and physical activity between the subtypes of IBS. The study was performed on outpatients diagnosed as irritable bowel syndrome (from January 2015 to December 2015) in Dhaka Medical College Hospital and Shaheed Suhrawardy Medical College Hospital in Dhaka. A total of purposively selected 208 diagnosed IBS patients were interviewed by semi-structured questionnaire in which subtype of irritable bowel syndrome were measured by Rome-III criteria regarding stool consistency.

Results: Mean age of the respondents was $32.3(+10.32)$ years and majority of them were male (77\%), married (66.8\%), educated up to secondary level (35.6\%), labour (skilled and unskilled) (30\%), non-smoker (67.3\%) and HEPA (health enhancing physical activity) active (65.9\%). Diarrhea predominant irritable bowel syndrome (50\%) was found the most common subtype among the irritable bowel syndrome respondents followed by mixed type irritable bowel syndrome $(42 \%)$ and constipation predominant irritable bowel syndrome (8\%) There were no statistical differences found between constipation predominant irritable bowel syndrome (IBS-C), Diarrhea predominant irritable bowel syndrome (IBS-D), and mixed type irritable bowel syndrome (IBS$M)$ patients regarding to socio-demographic characteristics and lifestyle factors $(\mathrm{P}<0.05)$.

Conclusion: Our study concluded that there are no different socio-demographic and lifestyle characteristics between IBS subtypes.

[J Shaheed Suhrawardy Med Coll 2017; 9(1): 6-9] DOI: http://dx.doi.org/10.3329/jssmc.v9i1.37251

1. Dr. Sadia Rahman Chowdhury, MPH (Epidemiology), Assistant Professor (CC), Department of Community Medicine, Jalalabad Ragib Rabeya Medical College, Sylhet.

2. Syed Alamgir Safwath, MD (Gastroenterology), Associate Professor, Department Gastroenterology, Jalalabad Ragib Rabeya Medical College, Sylhet.

3. Dr. Dilip Kumar Ghosh, FCPS (Med.), MD (Gastroenterology) Associate Professor, Department of Gastroenterology, Shaheed Suhrawardy Medical College, Dhaka.

4. Dr. Mohammad Mahmuduzzaman, MD (Gastroenterology), Associate Professor, Department of Gastroenterology, Shaheed Suhrawardy Medical College, Dhaka.

5. Dr. Madhusudan Saha, MD (Gastroenterology), Professor, Department of Gastroenterology, North-East Medical College, Sylhet.

6. Dr. Md. Jahangir Alam, MD (Gastroenterology), Associate Professor, Department of Gastroenterology, Sylhet M A G Osmani Medical College, Sylhet.

7. Dr. Muiz Uddin Ahmed Choudhury, Senior Lecturer, Department of Community Medicine, Jalalabad Ragib Rabeya Medical College, Sylhet.

Correspondence: Dr. Sadia Rahman Chowdhury, Assistant Professor (CC), Community Medicine, Jalalabad Ragib Rabeya Medical College. Mobile: + 8801717064724, Email: sadiarahman chowdhury@yahoo.com

\section{Introduction}

Irritable bowel syndrome (IBS) is one of the most common functional gastrointestinal (GI) disorders ${ }^{1,2}$. It is defined as the presence of abdominal pain or discomfort in association with altered bowel habits in the absence of any structural, physiological, or biochemical abnormalities in the GI tract ${ }^{3}$. The world wide prevalence of IBS varies according to the location, diagnostic criteria, and design of the study from $2.1 \%$ to $22 \%{ }^{4}$. It has been estimated that $5 \%-10 \%$ of the adult populations in Asian countries and $10 \%-20 \%$ of the populations in developed countries are affected by IBS ${ }^{5,6}$. Studies found that IBS is one of the most common outpatient diagnoses in primary care and gastroenterology and imposes a significant burden on healthcare systems due to its prevalence and lack of successful treatments ${ }^{7}$.

IBS is highly influenced by demographic factors, particularly sex and age ${ }^{8,9}$. It also interferes with their 
education, working ability and social life ${ }^{10 .}$ Although a range of studies concerning IBS has been conducted in other countries but to our knowledge there are few studies conducted on the investigation of socio-demographic and lifestyle factors in IBS patients in our country.

We aimed to investigate whether socio-demographic characteristics and lifestyle factors differ between subtypes of IBS as defined by the Rome III criteria.

\section{Methodology:}

A cross-sectional study was done among purposively selected 208 respondents visited by gastroenterologist and diagnosed as irritable bowel syndrome (IBS) at gastroenterology out-patient department of Dhaka Medical College Hospital and Shaheed Suhrawardy Medical College Hospital in Dhaka. Both male and female patients who are willing to participate with age between 16 to 60 years were included and pregnant women and severely ill patients were excluded from the study. The study questionnaire was included the following sections based on (i) Socio-demographic characteristics (ii) Lifestyle factor including smoking status and physical activity. (iii) Rome-III diagnostic criteria for type of IBS.

In this study the International Physical Activity Questionnaires (IPAQ) short form (Version 2.0. April 2004) was used to obtain internationally comparable data on health-related physical activity which includes items structured to provide separate scores on three specific types of activity (walking, moderate-intensity activities and vigorous intensity activities). On the basis of these scores physical activity was categorized into 3 categories: I) inactive, II) minimally active and III) HEPA active. The Rome III Committee simplified the IBS subtype classification using the criteria for stool consistency. IBS patients were categorized into constipation predominant IBS (IBS-C) if they had hard or lumpy stools with no loose, watery mushy or watery stools in the past 3 months; diarrhea predominant IBS (IBS-D) if they had loose, mushy or water stools in the last 3 months with no hard or lumpy stools; and mixed IBS (IBS-M) if they had both loose and hard stools in the past 3 months.

After explanation of the study aim, patients were asked to give their written consent to participate. The study received approval from Ethics Committee.

Continuous variables are presented as mean \pm standard deviation and categorized data as frequency and percentage. Appropriate statistical tests were used for data analysis done by software SPSS program version 16. All statistical tests were two-sided, and $P$ values less than 0.05 were considered significant.

\section{Result:}

Two hundred eight IBS patients (77\% males, $23 \%$ females) were enrolled to the study and their average age was 32.3 $(+10.32)$ years. Majority of the patients under study were found married $(66.8 \%)$, educated up to secondary level $(35.6 \%)$ and labour (skilled and unskilled) (30\%). Data regarding lifestyle factors showed that majority of the respondents were non-smoker $(67.3 \%)$ which included all female respondents and $57.5 \%$ of male respondents. Among male smokers, 24.5\% were smoking currently, smoked only cigarettes and took 1 to 20 sticks per day. Physical activity was dichotomized in this study. Majority of the respondents was found HEPA (health enhancing physical activity) active (65.9\%) where as the rest were minimally active (34.1\%).

IBS-D was the most common subtype of IBS among the respondents (50\%), followed by IBS-M (42\%), and IBS-C $(8 \%)$. The socio-demographic characteristics, smoking status and physical activity were compared among the different subtypes of IBS. This study revealed that there were no statistical differences between IBS-C, IBS-D, and IBS-M patients regarding to socio-demographic (Table 1 $\& 2)$ and lifestyle factors $(P>0.05)$ (Table 3$)$.

\section{Table-I}

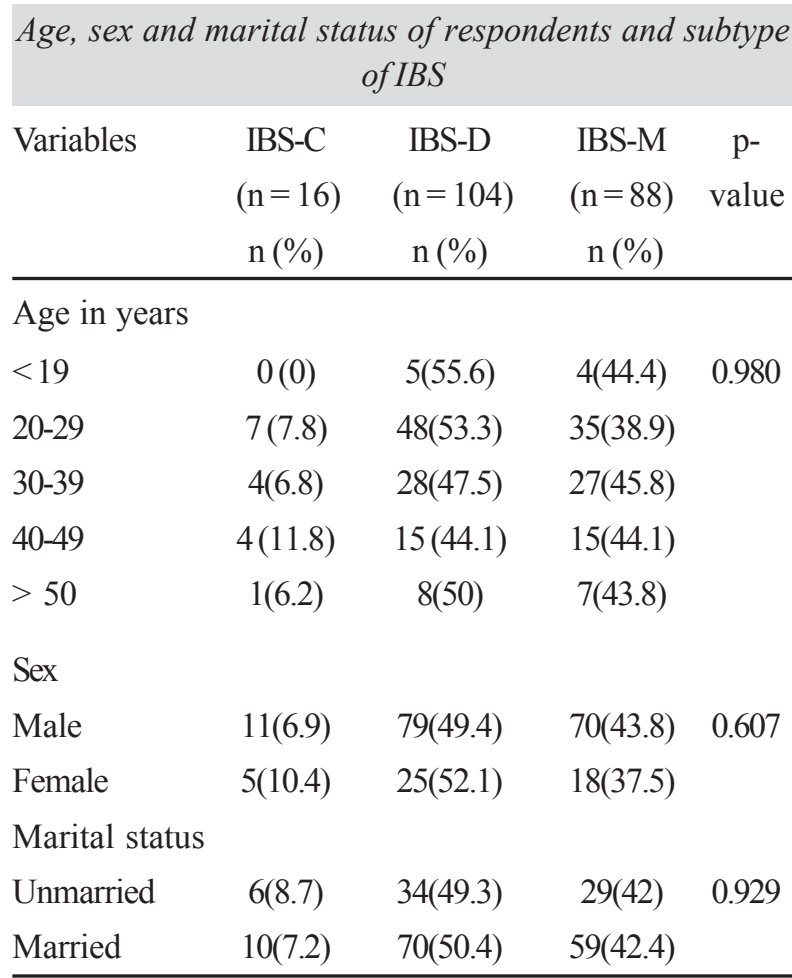

IBS - Irritable bowel syndrome. 
Table-II

\begin{tabular}{|c|c|c|c|c|}
\hline \multicolumn{5}{|c|}{$\begin{array}{c}\text { Educational level and occupational status of } \\
\text { respondents and subtype of IBS }\end{array}$} \\
\hline Variables & $\begin{array}{c}\text { IBS-C } \\
(\mathrm{n}=16) \\
\mathrm{n}(\%)\end{array}$ & $\begin{array}{c}\text { IBS-D } \\
(\mathrm{n}=104) \\
\mathrm{n}(\%)\end{array}$ & $\begin{array}{c}\text { IBS-M } \\
(\mathrm{n}=88) \\
\mathrm{n}(\%)\end{array}$ & $\begin{array}{c}\text { p- } \\
\text { value }\end{array}$ \\
\hline \multicolumn{5}{|l|}{ Educational level } \\
\hline $\begin{array}{l}\text { Illiterate and } \\
\text { can sign only }\end{array}$ & $0(0)$ & $5(41.7)$ & $7(58.3)$ & 0.276 \\
\hline Primary & $5(14.7)$ & $17(50)$ & $12(35.3)$ & \\
\hline Secondary & $8(10.8)$ & $39(52.7)$ & $27(36.5)$ & \\
\hline Higher secondary & $3(5.5)$ & $28(50.9)$ & 24(43.6) & \\
\hline $\begin{array}{l}\text { Graduation } \\
\text { and above }\end{array}$ & $O(0)$ & $15(45.5)$ & $18(54.5)$ & \\
\hline \multicolumn{5}{|c|}{ Occupational status } \\
\hline Unemployed & $1(2.1)$ & $30(62.5)$ & $17(35.4)$ & 0.079 \\
\hline Service holder & $5(12.2)$ & $12(29.3)$ & $24(58.5)$ & \\
\hline Businessmen & $3(11.5)$ & $11(42.3)$ & $12(46.2)$ & \\
\hline Housewife & $2(6.7)$ & $17(56.7)$ & 11(36.7) & \\
\hline $\begin{array}{l}\text { Labour (Unskilled } \\
\text { \& skilled) }\end{array}$ & $5(7.9)$ & $34(54)$ & $24(38.1)$ & \\
\hline
\end{tabular}

IBS - Irritable bowel syndrome.

Table-III

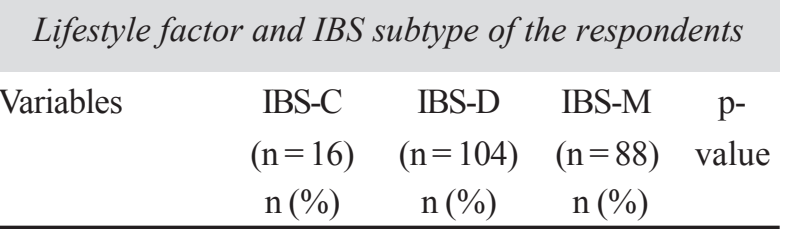

Smoking status (male respondents)

$\begin{array}{lcccc}\text { Never smoker } & 7(7.6) & 42(45.7) & 43(46.7) & 0.567 \\ \text { Past smoker } & 0(0) & 11(64.7) & 6(35.3) & \\ \text { Current smoker } & 4(7.8) & 26(51) & 21(41.2) & \end{array}$

Physical activity

\begin{tabular}{lcccc} 
Minimally active & $3(4.2)$ & $41(57.7)$ & $27(38.0)$ & 0.179 \\
HEPA active & $13(9.5)$ & $63(46.0)$ & $61(44.5)$ & \\
\hline
\end{tabular}

IBS - Irritable bowel syndrome. HEPA - Health enhancing physically active.

\section{Discussion:}

The purpose of this study was to ascertain if there were any differences between the subtypes of IBS regarding to the socio-demographic and lifestyle factors but found that there were no statistical differences among subtypes of IBS.

In this study, the average age of the respondents was 32.3 $(+10.32)$ years and majority of respondents were found between 20 to 29 years old (43.3\%). The age of IBS patients was consistent with a prevalence study done in urban community of Bangladesh ${ }^{11}$. The study mentioned that mean age of the IBS patients is $32.18(+12.98)$ and the majority of the IBS cases are in the 15-44 years' age group. Farzaneh et al. ${ }^{12}$ also found mean age of IBS patients is $33.9( \pm 11.8)$ years in their study.

It was found in this study that male respondents were $77 \%$ whereas females were 23\%. A study done in Pakistan found also male predominance among IBS patients ${ }^{13}$. The study revealed that higher proportion of respondents were married (63.5\%), educated up to secondary level (35.6\%) and labour (skilled and unskilled - 30\%). Other study has been reported that IBS patients are more likely to be married and less educated ${ }^{1}$. However, marital status was not related to IBS in other studies 14,15 . IBS was not related to the educational level among Chinese, Iranian and Korean adults $14,16 \& 17$.

Majority of the respondents with IBS of this study were never smoker (67.3\%) and more physically active (HEPA active $-65.9 \%$ ). No female smoker was found in this study. In a similar study, Farzaneh et al. ${ }^{18}$ found no association between smoking and IBS. Some studies have shown that smoking habit is significantly associated with gastrointestinal disorders such as IBS and the IBS participants were more physically active than the non-IBS participants, as evaluated by physical activity level (PAL) 19,20. Another study showed subjects who are physically inactive are 3.58 times more likely to suffer from IBS than those who are physically active ${ }^{21}$. These conflicting results might be attributed to the study design, diagnostic criteria used and cultural differences.

The study found that IBS-D (50\%) was more common subtype of IBS among respondents than IBS-M (42\%) and IBS-C (8\%). The prevalence of IBS-D was found highest may be because Perveen et al. ${ }^{22}$ mentioned IBS-D as the most prevalent subtype which is in accordance with previous urban study of Bangladesh. This finding is contrary to the study of Farzaneh et al. ${ }^{18}$ done in Iran which showed that IBS-C is the most frequent subtype of IBS patients seen by gastroenterologist.

Most of the subjects fulfilling the IBS criteria in both genders were IBS-D (49.4\% in males and $52.1 \%$ in females), followed by IBS-M and IBS-C in this study. Consistent with other studies, no statistical differences were seen between male and female regarding subtype of IBS ${ }^{18}$. Marital status and educational level were not significantly different among IBS subtypes and Keshteli et al. ${ }^{23}$ also found similar result. 
The proportion of IBS-D was found most common in unemployed (62.5\%) where as proportion of IBS-M was highest in service holder (58.5\%) and middle class (43.6\%). The proportion of IBS-C was also found highest in service holder $(12.2 \%)$. There was no statistically significant association found between occupational and economic status of respondents and IBS subtype.

This study found no statistically significant association between physical activity and IBS subtype of the respondents $(p>0.05)$. So far no studies have been found showing the association between smoking status and subtype of IBS.

No significant association was found between smoking status and IBS subtype among male respondents but some studies have shown that smoking habit is significantly associated with diarrhea-pre-dominant IBS ${ }^{24}$.

In conclusion, we could not find any significant differences between subtypes of IBS regarding to the sociodemographic and lifestyle factors. Future researches are needed with larger sample size from both treatment-seeking and non-treatment-seeking to be able to generalize the results.

\section{References:}

1. Khoshkrood-Mansoori B, Pourhoseinggholi MA, Safaee A, et al. Irritable bowel syndrome; a population based study. J GastrointestinLiver Dis. 2009; 18(4):413-418.

2. Sorouri M, Pourhoseinggholi MA, vahedi M,et al. Functional bowel disorders in Iranian population using RomeIII criteria. Saudi J Gastroenterol. 2010; 16(3):154-60.

3. Fan YJ, Chen SJ, Yu YC, et al. A probiotic treatment containing Lactobacillus, Bifidobacterium and Enterococcus improves IBS symptoms in an open label trial. J Zhejiang Univ-Sci B (Biomed \& Biotechnol). 2006; 7(12): 987-991.

4. Rey E, Talley NJ. Irritable bowel syndrome: novel views on the epidemiology and potential risk factors. Dig Liver Dis. $2009 ; 41: 772-780$.

5. Choi MG and Jung HK. Healthrelated quality of life in functional gastrointestinal disorders in Asia. J Neurogastroenterol Motil. 2011; 17(3): 245-251.

6. Camilleri M. Peripheral mechanisms in Irritable bowel syndrome. N Engl J Med. 2012; 367(17):1626-35.

7. Jung HK, Kim YH, Park JY, et al. Estimating the burden of irritable bowel syndrome: analysis of a nationwide korean database. J Neurogastroenterol Motil. 2014; 20(2):242-52.

8. Whitehead WE, Drossman DA. Validation of symptom-based diagnostic criteria for irritable bowel syndrome: a critical review. Am J Gastroenterol. 2010; 105:814-20.

9. Choung RS, Locke GR. Epidemiology of IBS. Gastroenterol Clin North Am. 2011;40:1-10.

10. Gralnek IM, Hays RD, Kilbourne AM, Chang L, Mayer EA. Racial differences in the impact of irritable bowel syndrome on health-related quality of life. J Clin Gastroenterol. 2004; $38: 782-789$.
11. Perveen I, Hasan M, Masud MA, Bhuiyan MM, Rahman MM. Irritable bowel syndrome in Bangladeshi urban community: prevalence and health-care seeking pattern . Saudi J Gastroenterol. 2009; 15(4): 239-243.

12. Farzaneh N, Ghobakhlou M, Dehkordi B, Naderi M, Fadai F. Evaluation of Psychological Aspects Among Subtypes of Irritable Bowel Syndrome. Indian J Psychol. 2012; 34(2): 144-148.

13. Butt AS, Salih M and Jafri W. Irritable bowel syndrome and psychiatric disorders in Pakistan: a case control study. Gastroenterol Res Pract. 2012; 291452.

14. Khademolhosseini F, Mehrabani D, Nejabat M, et al. Irritable bowel syndrome in adults over 35 years in Shiraz, southern Iran: prevalence and associated factors. J Res Med Sci. 2011; 16:200-206.

15. Sperber AD, Shvartzman P, Friger M, Fich A. Unexpectedly low prevalence rates of IBS among adult Israeli Jews. Neurogastroenterol Motil. 2005; 17:207-211.

16. Han SH, Lee OY, Bae SC, et al. Prevalence of irritable bowel syndrome in Korea: population-based survey using the Rome II criteria. J Gastroenterol Hepatol. 2006; 21:1687-1692.

17. Xiong LS, Chen MH, Chen HX, Xu AG, Wang WA, Hu PJ. A population-based epidemiologic study of irritable bowel syndrome in South China: stratified randomized study by cluster sampling. Aliment Pharmacol Ther. 2004; 19:12171224

18. Farzaneh N, GhobaklouM, Moghimi-Dehkordi B, Naderi N, Fadai F. Effects of Demographic Factors, Body Mass Index, Alcohol Drinking and Smoking Habits on Irritable Bowel Syndrome: A Case Control Study. Ann Med Health Sci Res. 2013; 3(3): 391-396.

19. Reshetnikov OV, Kurilovich SA, Denisova DV, Zavßalova LG, Svetlova IO, Tereshonok IN, et al. Prevalence and risk factors of the development of irritable bowel syndrome in adolescents: A population study. Ter Arkh. 2001; 73:24-9.

20. Omagari K, Murayama T, Tanaka Y, Yoshikawa C, Inoue $\mathrm{S}$, Ichimura $\mathrm{M}$, et al. Mental, physical, dietary, and nutritional effects on irritable bowel syndrome in young Japanese women. Intern Med. 2013; 52(12):1295-301.

21. Guo YB, Zhuang KM, Kuang L, Zhan Q, Wang XF, Liu SD. Association between Diet and Lifestyle Habits and Irritable Bowel Syndrome: A Case-Control Study. Gut Liver. 2015; 9(5):649-56.

22. Perveen I, Rahman MM, Shaha M, Rahman MM, Hasan MQ. Prevalence of irritable bowel syndrome and functional dyspepsia, overlapping symptoms, and associated factors in a general population of Bangladesh. Indian J Gastroenterol. 2014; 33(3):265-73.

23. Keshteli AH, Dehestani B, Daghaghzadeh H and Adibi P. Epidemiological features of irritable bowel syndrome and its subtypes among Iranian adults. Ann Gastroenterol. 2015; 28(2): 253-258.

24. Kubo M, Fujiwara Y, Shiba M, Kohata Y, Yamagami H, Tanigawa $T$, et al. Differences between risk factors among irritable bowel syndrome subtypes in Japanese adults. Neurogastroenterol Motil. 2011; 23:249-54. 